\title{
REVENDO A FUNÇÃO DA TRADUÇÃO NA SALA DE AULA
}

\section{Kyoko Sekino ${ }^{1}$}

Resumo; O artigo trata do uso da tradução como uma ferramenta em potencial para a aprendizagem de línguas estrangeiras. A fim de desenvolver a discussão metodológica da tradução pedagógica, é preciso distingui-la da tradução profissional. Do ponto de vista da tradução pedagógica, analisa-se a característica da tradução como uma habilidade inata do ser humano e seu engajamento natural e espontâneo na sala de aula. Discutem-se as críticas acerca da tradução e, com o intuito de sustentar os pontos positivos de suas características, apresentam-se alguns usos desta ferramenta, concluindo que ela poderá ser mais ativamente empregada para promover a atividade cognitiva dos alunos de LE. Palavras-chave: tradução natural; tradução pedagógica; tradução profissional; tradução como ferramenta da aprendizagem de línguas estrangeiras.

Abstract: This article discusses the use of translation as a potential tool of learning foreign languages (LEs). In order to develop the methodological discussion, it is treated separated from the professional translation. In the point of view of the pedagogic translation, it analyzes the characteristics of the translation as an innate ability of the human and its natural and spontaneous engagement in the class room. It discusses the critics about translation and it presents some example of its use as a tool in order to show the positive characteristics. It is concluded, therefore, translation may be more actively employed to promote the cognitive activity of the LE learners.

Keyword: natural translation; pedagogic translation; professional translation; translation as a foreign language learning tool.

1. Doutoranda em PosLin (Programa de Pós-Graduação em Estudos Linguísticos) da Faculdade de Letras da Universidade Federal de Minas Gerais (UFMG). Professora Assistente do Instituto de Letras da Universidade de Brasília (UnB). 


\section{Introdução}

Usa-se o termo tradução em vários sentidos: por exemplo, quando as crianças bilíngues desempenham troca de línguas na comunicação com facilidade, pode-se dizer que estão praticando a tradução obviamente; Alunos de língua estrangeira/ segunda língua (LE/L2) também praticam a tradução ao compreender frases e orações em LE/L2. Frequentemente professores perguntam o significado de alguma frase na sala de aula. A resposta dos alunos é uma tradução, respondendo o significado em sua língua materna (LM). Existem, por outro lado, profissionais que executam a tradução oral e escrita. Caso destes, tiveram treinamento e experiência para desempenhar o papel social como tradutor/interprete profissional.

Estes exemplos exibem a variedade de tradução, sendo variantes em continuum. Contudo, observa-se um tipo de dicotomia em quem pratica tradução, isto é, leigo ou profissional. As crianças e os alunos praticam a tradução sem consciência de executar tarefa de tradução, caracterizando-se como tradução natural ou mediação de línguas. No caso dos tradutores, são especialistas que têm tido treinamento a modo que desempenham o papel de tradutor profissional. Sua competência tradutória não é apenas mediação bilíngue ou multilíngue, mas, uma tarefa de buscar equivalência mais adequada em outra língua para audiência.

Neste artigo, enfoca-se na tradução e no tratamento dado à tradução no ensino de (LE/L2), especialmente no âmbito do ensino da língua japonesa no Brasil. Em geral, observa-se que a tradução é tratada de forma discriminada no ensino de LE/ L2, subutilizada na sala de aula devido à valorização do método comunicativo $\mathrm{e}$ ao abandono do Método da Gramática e Tradução. Por outro lado, consta-nos que professores cobram dos alunos a tradução no nível de frase e de léxico, tanto para LE (tradução inversa) como para LM (tradução direta). Apesar do seu uso secundário, ou seja, a tradução nunca constitui o foco principal no ensino/aprendizagem de LE/L2, parece estar sendo freqüentemente usada na sala de aula até sem que os profissionais tenham consciência da função da tradução.

$\mathrm{Na}$ medida em que a língua japonesa é bastante distante do português - a LM da maioria dos alunos brasileiros -, a tradução torna-se uma importante ferramenta para o ensino daquela língua para eles, oferecendo um maior apoio para a compreensão do significado e do mecanismo dessa língua.

Nesse sentido, propomo-nos, primeiro, a discutir a tradução como uma atividade rudimentar do ser humano. Depois, passaremos a refletir sobre o papel desempenhado pela tradução na aquisição da LE. Veremos também alguns métodos sugeridos por vários pesquisadores, apresentando, por fim, as experiências que tivemos em sala de aula, uma dinâmica observada com relação à tradução, ressaltando a diferença entre as traduções pedagógica e profissional. Assim, não se trata de pesquisa, mas, exploraremos a possibilidade da tradução como ferramenta na sala de aula, distinguindo a tradução de mediação, tradução natural e tradução 
pedagógica de tradução profissional, revendo o uso da tradução na sala de aula sugerido por vários autores e a prática realizada na sala de aula.

\section{Mediação e Tradução}

Em primeiro lugar, refletimos se a tradução tem o mesmo sentido que a mediação, isto é, uma habilidade rudimentar do ser humano. Darwish (2000) questiona, em seu artigo, a diferença entre atividade inata e atividade natural do ser humano. Primeiro, o autor revisa o funcionamento do cérebro humano em relação à língua. Mesmo que não se use ou não se fale uma língua (LM, em especial) por um período, ela não é esquecida. A língua vive enquanto o cérebro vive, ou seja, enquanto o cérebro pensa. Conclui que tanto o cérebro como a língua são naturais para o ser humano. Formula, contudo, a mesma questão para outras atividades linguísticas tal como escrever, em que essa habilidade não se mantém quando se fica sem praticá-la. $O$ escrever necessita de treinamento constante para se desenvolver. Pode-se estender a mesma analogia para a tradução.

Darwish afirma que a habilidade de tradução é inata, mas não natural, visto que ela é adquirida através de treinamento e experiência, atendendo às necessidades. O autor defende que "se a qualidade de ser natural é caracterizada por espontaneidade e pela liberdade de artificialidade, afeição e inibição, a tradução não é natural"'(p.1). Do mesmo modo, ele estende essa discussão também ao bilinguismo. Os bilíngues não estão sempre no modo bilíngue, ao qual acendem conscientemente de acordo com as circunstâncias. Sustenta, portanto, que há alternância para o modo bilíngue.

Retomando as discussões tradicionais sobre a "tradução natural", o autor apresenta a teoria de Harris (1976) $)^{3}$ e Harris \& Sherwood (1978) $)^{4}$, na qual a tradução natural é observada em crianças bilíngues, caracterizando-se por ser um comportamento que dispensa treinamento, uma vez que se trata de uma atividade primitiva e rudimentar. Sua tradução se restringe a um nível elementar como uma tradução de unidades lexicais ou de algum conceito abstrato mais simples. Para se tornarem intérpretes no futuro, elas necessitam de treinamentos.

Para Toury ${ }^{5}$ (1995), referido por Darwish, as hipóteses sobre a habilidade tradutória inata não dão conta de explicar a emergência da tradução como uma

2. (original) If natural is the state of something characterized by spontaneity and freedom from artificiality, affectation, or inhibitions, then translation is not natural.

3. HARRIS, B. The Importance of Natural Translation, Working Papers. In Translatology 2. Ottawa, School of Translators and Interpreters, University of Ottawa, 1976.

4. HARRIS, B and SHERWOOD. B.. Translating as an Innate Skill. In: GERVER, D. \& SINAIKO, H. (Eds.), Language, Interpretation and Communication. Plenum Press, New York. 1978.

5. TOURY, G. Descriptive Translation Studies and Beyond. John Benjamins. Amsterdam, 1995. 
habilidade treinada e que a aquisição da habilidade tradutória não equivale ao mero desenvolvimento da predisposição inata.

Pela interpretação de Lörscher (1994), a tradução natural, defendida por Harris e Sherwood, refere-se a uma competência de mediar línguas, e não a uma tradução propriamente dita. Nesse ponto, Toury concorda com Harris e Sherwood especialmente no que concerne a uma habilidade predisposta do ser humano, assim como na tese de que constitui uma extensão do desenvolvimento bilíngüe. No entanto, argumenta que a competência tradutória não se desenvolve (quase) automaticamente, nem paralela ao desenvolvimento do bilinguismo das crianças. Ainda defende que o bilinguismo, por sua vez, não é suficiente para o desenvolvimento da competência tradutória, embora admita que é precondição desta competência.

Após uma cautelosa revisão teórica, Lörscher toma uma posição medial dos teóricos, afirmando que "todo o individuo que tem comando de duas ou mais línguas também possui uma habilidade rudimentar de mediar as línguas" (p.41). No entanto, o autor questiona, primeiro, o conceito de tradução. De acordo com Lörscher, a tradução é uma atividade baseada em textos. Quando se traduz um texto de uma língua para outra, deve haver algum objetivo nesta tarefa. De acordo com os objetivos, diferem, na tradução, o sentido, a função, o estilo, o tipo textual e outros.

No âmbito profissional dos tradutores, a mediação é diferente da que ocorre na dos bilíngues precoces. Conseqüentemente, as teorias da tradução somente se aplicam ao comportamento dos tradutores eminentemente treinados como profissionais. Logo, a tradução natural, em que se envolvem crianças bilíngües que praticam a mediação em sua tenra idade, deveria ser questionada como termo de comparação.

Do mesmo modo, a tradução praticada no ensino de uma L2 deve merecer um tratamento diferenciado do da tradução profissional. Evidencia-se a mediação rudimentar no início do processo de aquisição de L2. Na sala de aula, os alunos começam a praticar a tradução elementar.

Referindo-se a Ringbom ${ }^{6}$, Lörscher concorda que os alunos de L2 estão constantemente à procura de algo para facilitar sua aprendizagem e superar suas dificuldades, usando todos os conhecimentos previamente obtidos, entre os quais o conhecimento já obtido da língua de estudo, além do da LM ou de outras línguas. Observa também que os alunos sempre procuram se relacionar com os novos conhecimentos adquiridos da L2 a fim de melhor desenvolver a própria L2, cujo conhecimento ainda é extremamente limitado. Constata-se, pois, que nessa fase, os alunos "sistematicamente recaem na língua materna. Esta funciona como um filtro, através do qual a língua estrangeira é recebida e produzida"' (Lörscher, p.45).

6. RINGBOM, H (ed.) Foreign Language Learning and Bilingualism. Abo, 1985.

7. (original) learners often systematically relapse into their mother tongue. It functions like a filter through which the foreign language is received and produced. 
Considera-se este comportamento, observado no início da aquisição da L2, como a primeira marca da mediação que, preliminarmente, denominaremos tradução emergente. A tradução, portanto, pode exprimir vários conceitos diferentes, dependendo do usuário, a saber: tradução (profissional), tradução natural (praticada por bilíngues precoces) e tradução emergente (praticada pelos alunos, talvez mentalmente, na sala de aula de LE).

Com o intuito de discutir o uso da tradução na sala de aula, temos que tomar cautela em usar o conceito de tradução, pois o termo é definido para o âmbito de tradutores profissionais, o qual não se aplica ao universo do ensino/aprendizagem de línguas estrangeiras.

\section{Tradução no Âmbito de Ensino/Aprendizagem de Línguas Estrangeiras (LE/L2)}

House (2009) discute o uso da tradução no ensino de LEs. Sem dúvida, a tradução é conhecida como um método mantido durante um longo período no ensino de LE. Mesmo sendo criticada após o surgimento da abordagem natural e método direto, a tradução continua sendo usada, até hoje, em sala de aula. A autora revisa seu uso, levantando alguns pontos positivos. Por exemplo, a tradução ajuda o desenvolvimento da proficiência, explicando o significado de itens da LE sem perda de tempo, sem ambigüidade. A intermediação de uma língua familiar dos alunos, como a LM, permite que os alunos trabalhem com mais confiança, assegurando a motivação para aprender uma LE.

A tradução permite explicitar o nível de conhecimento sobre a LE adquirido pelo aluno e ajuda-os a desenvolver sua percepção de diferenças e semelhanças. Nesse ponto, Lörscher (1994) também acredita que a percepção de semelhanças e dessemelhanças, assim como a capacidade de categorizar e de comparar, é uma das características da inteligência do ser humano. Ademais, a percepção sobre as línguas, realçada pela tradução, tem amplos benefícios educacionais, desde que esta promova a compreensão transcultural. Nesse ponto, a tradução é o ponto de partida para o desenvolvimento da observação e discussão sobre língua e cultura, especialmente, sobre a especificidade de cada cultura e a universalidade, tais como formas e funções das expressões de polidez culturalmente condicionadas, de expressões indiretas, conotação, entre outros.

A tradução é praticada individualmente, mas, pode ser usáda na prática de comunicação envolvendo alguns alunos, fazendo com que o texto traduzido por um aluno seja passado para outro, para ver se compreendem a mensagem.

Por outro lado, House também discute a crítica feita ao uso pedagógico da tradução. Levanta-se, em primeiro lugar, o problema da interferência. Apesar de seu alerta de que não há evidências em pesquisas experimentais, a tradução pode, 
nas produções de LE, causar interferência no processo natural de aquisição da LE, pela coexistência da LM com a LE. Os aprendizes acabam recebendo alguma influência da LE, em processo de aprendizagem, que acaba interferindo na LM.

Mais oposição à tradução foi identificada na discussão sobre a formação de bilíngües, apesar de House apontar que não há nenhuma prova de que a tradução induza ao tipo "errôneo" de bilinguismo, isto é, o bilíngue composto. No entanto, observa-se que a discussão sobre o bilinguismo coordenado ou composto vem sendo questionada nos anos recentes. Também no uso da tradução para a avaliação da aquisição e assimilação dos conhecimentos passados aos alunos, constata que a tradução não avalia a proficiência de LE dos alunos, mas, sim, da habilidade da tradução. Alguns pesquisadores, portanto, contestam o uso da tradução na avaliação da proficiência dos alunos.

House, então, conclui que ainda se constata uma ampla suspeita sobre a utilidade da tradução no ensino de LE. Esta suspeita deve se originar da tese de que não há lugar para a LM na aprendizagem de LE. No entanto, a autora acredita que a "tradução (...) pode ser usado para fazer os aprendizes refletirem nas diferenças e semelhanças nas características formais dos sistemas linguísticos de L1 e L2 e também de sentidos contextual e cultural dos textos original e traduzido." (p.69)

Brown também defende a mesma posição, comentando sobre a aprendizagem de LE por alunos adultos que "tentam formular regras linguísticas na base de qualquer informação disponível: informação da língua nativa, da L2, dos professores e colegas" E conclui que:

adultos, cognitivamente mais seguros, parecem operar a L2 da fundação sólida da L1, assim, manifestam mais interferência. [...] A L1, no entanto, pode ser mais usada prontamente para construir ponte entre duas línguas que o aprendiz-adulto não consegue estreitar a lacuna destas línguas por generalização na L2. Nesse caso, temos que nos lembrar bem que a L1 pode ser fator facilitador, mas não apenas fator de interferência ${ }^{9}(2000$, p.68).

Estudos recentes parecem mostrar a revalorização do uso de LM, incluindo o uso pontual como alternância de línguas (code-switching) e recuperação do seu papel como língua de comando e de explicação na sala de aula (Usadiati, 2009; Nazary, 2008; Matiolli,2004; Shiyab e Abdullateef, 2001), A tradução, como envolve uma atividade cognitiva de carga pesada (Lörscher), deveria desempenhar

8. (original) the translation (...) can be used to make learners reffect on differences and similarities in the formal features of $\mathrm{L} 1$ and $\mathrm{L} 2$ language systems as well as the contextual and cultural meanings of original and translated texts.

9. (original) Adults, more cognitively secure, appear to operate from the solid foundation of the first language and thus manifest more interference. (...) The first language, however, may be more readily used to bridge gaps that the adult learner cannot fill by generalization within the second language. 
mais papeis e trazer mais benefícios aos aprendizes para que eles possam observar semelhanças e diferenças entre as duas línguas e, assim, desenvolver o processo bilíngüe.

\section{A Tradução Pedagógica}

Kasmar (1999) se refere ao uso da tradução como o método de yakudoku ${ }^{10}$ Entende-se por yakudoku como o método de Gramática-Tradução, usado principalmente no ensino do inglês para falantes de japonês. Neste método, os alunos aprendem a LE pela leitura e tradução de textos em LE. Para tanto, precisam ter adquirido o conhecimento gramatical para poderem decodificar o texto.

Suas criticas sobre o método yakudoku estão nos seguintes pontos: os alunos se concentram somente na tradução de modo que negligenciam a comunicação; traduzem as sentenças palavra por palavra; o método é devagar, pois requer leitura excessiva, impedindo a compreensão da língua de meta. Conseqüentemente, o método yakudoku se mostra ineficaz para os aprendizes japoneses de LE, fazendo-os perderem a motivação de estudo. Ademais, a onda da abordagem comunicativa deve ter ajudado a realçar sua negatividade, o que é observado na implementação do Japanese Exchange and Teaching Program (JET) ${ }^{11}$ pelo governo japonês a partir de 1987, convidando professores de língua inglesa de quatro países (EUA, os Reinos Unidos, Austrália e Nova Zelândia) que, inseridos nas comunidades japonesas, deviam ensinar inglês nas escolas de ensino médio, a fim de que os alunos pudessem adquirir a habilidade comunicativa, principalmente oral e pragmática em inglês.

No yakudoku, o problema principal pode estar na compreensão que os professores têm sobre a tradução. Como já foi colocado, estamos naturalmente praticando a tradução (mental) em situações de contato com outra língua. Como a prática é tão natural, os professores nem se dão conta de verificar e revisar o mecanismo da tradução. Inclusive eles devem ter praticado o mesmo método quando foram alunos. Apesar da imagem de tradução como uma atividade profissional, se a LM tem um papel importante na aprendizagem de LE, a tradução, isto é, o contato entre duas línguas deverá ser rediscutida, revisada e, por conseguinte, introduzida na sala de aula de LE por parte dos professores.

10. 訳読（やくどく）, literalmente "ler textos em LE traduzindo" Os alunos são expostos a um texto de LE e lê-lo traduzindo. Este método serve-se para os alunos a verificação da sua aprendizagem da gramática, ao mesmo tempo, a assimilação do conhecimento gramatical e lexical.

11. Mas, por exemplo, em 1987 , o governo convidou um total de 848 jovens, entre os quais 813 foram ao Japão com o objetivo de trabalhar em escolas do ensino médio como assistente no ensino da língua inglesa. $O$ atual JET Program mudou seu perfil ampliando o raio do intercâmbio para outros países que não tenham o inglês como lingua pátria. (Fonte= http://www.jetprogramme.org/e/introduction/history.html) 
Para Alegre (2002), a tradução em seu uso pedagógico se manifesta sob a forma de exercício na sala de aula de LE, para os alunos desenvolverem a competência lingüística.

Historicamente, segundo a autora, nos anos 80 , houve uma redefinição da tradução pedagógica, "através de uma reflexão sobre a natureza da tradução, como atividade profissional" (p12). Citando alguns autores, a autora observa a revalorização da tradução pedagógica, inserindo-a na comunicação real, frisando sua praticidade no contexto comunicativo. Este movimento mostra uma atitude crítica à antiga prática do método da Gramática e Tradução, pela qual os aprendizes se defrontaram com a tradução de frases desprovidas de contexto.

A autora cita outros pesquisadores como Butzkamm (1993) que defende o uso da tradução para os alunos de níveis iniciantes, para os quais a recorrência à tradução sistemática auxilia o processo de semantização. Stern (1992), por sua vez, discute pontos positivos e negativos das estratégias interlinguais da tradução na aquisição de LE, favorecendo as técnicas que, de modo geral, "decorrem no sentido da LE para a LM" Também defende certas técnicas de tradução da LM para a LE como "um papel restrito de reforço ou de confirmação de conhecimentos lingüísticos já adquiridos através de estratégias intralinguais"

Ferrer (2005), por sua vez, aponta que, no início da aprendizagem comunicativa de LE, o foco estava quase completamente centrado no significado. Esta postura é contestada mais tarde pelos estudos sobre o papel da instrução focalizada na forma e de conhecimento lingüístico e explicito. De acordo com Alegre;

\footnotetext{
Uma dessas tendências consiste na actual valorização da aprendizagem consciente da LE, que se alia a um conhecimento explícito da língua, por oposição a teorias que valorizam a aprendizagem implícita, sem recurso à reflexão sobre o modo de funcionamento da língua. (2002, p.13, grifo nosso)
}

McLaughlin $^{12}$, de acordo com Alegre, levantou, a complexidade do processo cognitivo da aquisição de $\mathrm{L} 2$, porque o processo envolve representações mentais originalmente feitas na LM, as quais sofrem alterações e reestruturações por meio do contato com o novo sistema lingüístico.

No que concerne à habilidade de processar a aquisição, Bialystok e Smith (1985) analisam-na de outra forma. Os alunos acumulam conhecimento lingüístico e analítico da L2, nomeando-o "representação mental" Eles também tentam aprender usar seu conhecimento da L2, chamando-o "controle" Logo, os autores apontam que falantes não-nativos de uma língua podem obter nível mais alto do conhecimento lingüístico e analítico do que o falante nativo desta língua. No

12. Mclaughlin, B. Theories of the Second Language Learning. London, Edward Arnold, 1987. 
entanto, seu controle sobre esta língua está no nível mais baixo. Postularam que é este desequilíbrio que propicia a manifestação da interlíngua.

Entre a análise das regras gramaticais e o controle no uso da L2, a LM parece mediar, ou seja, se equilibrar entre análise e uso para compreender a LE. A este respeito, Alegre afirma que:

\begin{abstract}
Em que medida pode então um ensino de base cognitiva favorecer o recurso à LM? Trata-se, no fundo, de explicitar, de tornar consciente um processo interno que inevitavelmente tem lugar no nosso cérebro, pelo menos em fases de iniciação. $O$ confronto de determinados aspectos de LE com a LM, e vice-versa, justifica-se, a meu ver, em fases de reflexão sobre o modo de funcionamento da língua. (2002, p.13, grifo nosso)
\end{abstract}

Quando considera o que as crianças aprendem através do ensino de LE, Paiva (1998) explica que os alunos podem "aprender a aprender" O processo de aquisição da LE estimula os alunos a observar seu processo de aprendizagem, comparando semelhanças e diferenças entre as duas línguas. Assim se desenvolve a metacognição. A autora cita a opinião de $\mathrm{Abbott}^{13}$ dizendo que "devemos ser capazes de recuar, como especialistas, para refletir, reavaliar o que se faz..." (p.124)

Alegre evidencia através da teoria e da prática um grande número de técnicas existentes no ensino de LE, visto que há técnicas de aquisição de acordo com cada indivíduo ou cada estilo de aprendizagem. Conclui, então, que :

Uma conseqüência justa da percepção dos diferentes estilos de aprendizagem será a diversificação das técnicas de ensino e uma procura de equilíbrio entre fases de reflexão sobre a língua e fases de automatização, entre fases essencialmente receptivas e fases de utilização activa da língua. Neste sentido, a tradução - ou os diversos tipos de exercícios que a constituem - podem contribuir para um alargamento das estratégias de ensino. (2002, p.13)

A tradução, além da relevância do uso da LM, auxilia a aprendizagem dos alunos, especialmente na fase em que estes recebem informações lingüísticas básicas, para compreender e analisar a língua de meta e, em fase mais avançada, para produzir espontaneamente a partir do conhecimento já obtido. Seguindo as observações de Bialystok e Sharwood Smith (1985), a análise e o uso são identificados como duas colunas relevantes na aprendizagem de LE e o desequilíbrio

13. “Abbott (1997, p.9) salienta que uma das habilidades que deve ser mais enfatizada é a “...de pensar sobre o próprio pensamento..." ou metacognição. Para o autor, a metacognição é essencial no desenvolvimento de habilidades que são transferíveis e ligadas ao pensamento reflexivo". (Paiva, 1998, p.124). ABBOTT, J. To be intelligent. In: Educational Leadership :How children learn. v.54, n.6, Alexandria, Va: ASCD. p.6-10, March 1997. 
entre as duas pode ser diminuído por meio de várias técnicas de aprendizagem, entre as quais a tradução.

Alegre vê a importância da redefinição do papel da LM na aprendizagem da LE, na qual vai se estabelecendo uma ponte entre a cultura e a língua, e entre a cultura e a língua maternas e as estrangeiras. A autora reavalia a LM, reconhecendo nela as capacidades receptivas dos alunos e, assim, integra exercícios de tradução no sentido da LE à LM.

Ademais, a autora discute a diferença entre "recurso à LM" e "exercício de tradução" As referências relacionadas a este tema freqüentemente usam os dois termos indistintamente. Explica que há uma dificuldade de estabelecer a diferença entre as duas. No entanto, Alegre sustenta que "recursos à LM" é uma forma de utilização pontual da LM ou da tradução para facilitar a compreensão ou para avaliar esta compreensão. O "exercício de tradução" é também conhecida como "tradução pedagógica" e "se refere a um recurso consciente (pelo menos da parte do professor) à LM, através de um exercício de tradução de uma unidade de sentido, numa acepção lata do termo" (p.15).

Assim, discutimos vários aspectos da tradução no ensino de LE e percebemos que ainda há assuntos a serem analisados e discutidos sobre o uso da tradução pedagógica.

\section{Uso Atual e Experimental de Tradução na Sala de Aula}

Em um estudo anterior, aplicamos um método introspectivo, conhecido como Protocolo - Thinking aloud protocol - TAP, para uma pesquisa sobre a tradução observando o trabalho desenvolvido por dois alunos da área de japonês (2009). Usamos uma variedade do protocolo - o protocolo dialogado - pela qual os dois informantes da pesquisa conversam entre si para resolver a tradução da língua japonesa (LE) para a portuguesa (LM).

Os alunos escolheram traduzir, pelo seu interesse, a Constituição do Japão como uma das atividades extracurriculares. Foram programados encontros semanais para traduzir a Constituição discutindo, ou seja, "pensando alto" Para tanto, foi solicitado aos alunos que fizessem previamente um levantamento dos termos desconhecidos do texto e procedessem a uma tradução mental, ou seja, estruturar na mente mais ou menos como ficaria a tradução sem elaborá-la na forma de tradução escrita.

Esta experiência nos permitiu ver a eficácia do uso da tradução fora de sua forma convencional, ou seja, a de somente verificar o significado. Ela serviu para percebermos como se dá a associação, por parte dos alunos, da língua japonesa em termos de interlíngua (entre LE e LM) e de intralingua (dentro da LM ou dentro da LE). A título de exemplo, transcrevemos uma parte da conversa trocada 
entre estes alunos, B e F, sobre a expressão: 起こることのないやうにするこ $と$ [okorukotono naiyouni surukoto]:

<Transcrição>

B: 起こることのないやうにすること $\ldots .$.

F: Esse, por exemplo,にすする ....... parece que era mesma função de ..... como falou?, コーヒーにする. Então, se for nesse sentido de escolher ou esse tipo de função,

Nessa expressão fraseológica que envolve o verbo “fazer" (する), este varia muito de significado dependendo da combinação com outras palavras ou do contexto. Neste caso, する acompanhando a partícula にassume o sentido de decisão do falante. Assim, コーヒーにする, citado por F, expressa a decisão do falante em "tomar café": "decido por café", "escolho o café", "fico com o café" $\mathrm{O}$ informante $\mathrm{F}$, portanto, associou a frase com o que ele tinha aprendido, tentando inserir na frase este sentido de "decisão" sob a forma de "decidimos ..."

Alegre (2002) também aponta que a utilização da tradução em grupo é uma característica própria da sala de aula, diferentemente da tradução profissional do indivíduo (p.20). A partir desta observação, começamos a sistematicamente aplicar a tradução na sala de aula, fazendo com que os alunos discutissem mais sobre uma dada estrutura da língua japonesa.

Em outra oportunidade, provocamos a discussão acerca de uma partícula, envolvendo todos os alunos de uma sala de aula do $6^{\circ}$ semestre, de nível intermediário. Tratava-se da partícula で[de] da sentença:

距離的にも、2泊3日ぐらいで、ちょうどいいんじゃないかな。

[kyoriteki nimo, nihaku mikkagurai de choudoiinja naikana. "pela distância, uma viagem de duas noites e três dias não seria de bom tamanho?"]

Sem identificar a função indicada pela partícula で, os alunos começaram compreendendo a frase no sentido de: "Se for uma viagem de 2 noites e 3 dias, não será legal?" Quando indagamos a função sintática marcada pela partícula, eles responderam que se tratava de uma condicional.

Este é um exemplo que mostra como os alunos criaram uma tradução em português mais compreensível para eles, sem levar em conta a estrutura da frase japonesa. Pelo sentido da frase, até poderia ser traduzida por uma condicional. Nesse caso, entretanto, em japonês usar-se-iam partículas condicionais como 2 泊 3日ぐらいなら、2泊3日ぐらいであれば.A partícula でindica uma delimitação no eixo do tempo e não se usa como um conetivo condicional. 
Esta discussão dos alunos nos mostra a relevância da tradução interlingual, como uma ferramenta em potencial para entender e examinar a sintaxe japonesa. Ao mesmo tempo, a tradução também é útil para se compreender o sentido da frase. A discrepância entre as duas formas de tradução, a tradução fiel à forma e a tradução fiel à semântica, pode explicitar para os alunos como se estruturam e se comportam as línguas em contato.

No exemplo dado, teríamos a seguinte tradução literal e interlingual: "Pela distância também, por aproximadamente 2 noites e 3 dias, não ficaria justo?" Se esta frase ignora completamente a forma da língua portuguesa, ela ajuda a analisar e compreender a forma da língua japonesa. Além do que, os alunos podem não apenas identificar as semelhanças e diferenças entre as duas línguas, mas também observar o que é perdido ou omitido na transferência de uma língua para outra.

A fim de promover a percepção dos alunos, Kasmer (1999) também apresenta um método interessante, também por nós testado. Prepara-se uma folha com uma sentença escrita em LE que deverá ser traduzida para a LM por um primeiro aluno. Dobra-se a folha para esconder a frase original, passando-a ao segundo aluno que deverá traduzir para a LE a frase do colega precedente em LM. E assim segue a folha por toda a classe, alternando-se as traduções LE-LM e ocultando aquela precedentemente elaborada na língua alvo de sua tradução.

Segundo Kasmer, esse exercício permite que "os alunos examinem qual significado foi perdido na tradução das frases ${ }^{14}$ ", além de permitir que os alunos percebam as diferenças da estrutura gramatical e contextual entre as duas línguas.

Partindo, portanto, do princípio de que o que se perde na tradução é um guia da compreensão da LE pelo aluno, aplicamos esse método para uma turma do $8^{\circ}$ semestre, dividida em dois grupos. Para um primeiro grupo de seis alunos, passamos a frase “コンピューターを買おうと思います”[ [konpyutaa o kaou to omoimasu] que apresentou o seguinte comportamento.

\begin{tabular}{|l|l|}
\hline Original & コンピューターを買おうと思います。 \\
\hline Aluno 1 & Estou pensando em comprar um computador \\
\hline Aluno 2 & コンピューターを買おうと思っている。 \\
\hline Aluno 3 & Estou pensando em comprar um computador \\
\hline Aluno 4 & コンピゥータを買いて思っています。 \\
\hline Aluno 5 & Estou pensando em comprar um computador \\
\hline Aluno 6 & わたしはコンプィワータを買うにと思います。 \\
\hline
\end{tabular}

Para outro grupo de cinco alunos, aplicamos outra frase.

14. (original) ... students examine what meaning has been lost in the translation of the sentences. 


\begin{tabular}{|l|l|}
\hline Aluno1 & Eu fui ao Japão \\
\hline Aluno2 & 私は日本へ行きました。 \\
\hline Aluno3 & Eu vou ao Japão \\
\hline Aluno4 & 私は日本へ行く。 \\
\hline Aluno5 & Eu vou ao Japão \\
\hline
\end{tabular}

No primeiro grupo, nosso objetivo era verificar o uso da partícula de citação “と” antes do verbo 思う e o resultado mostrou que os alunos tinham assimilado bem este quesito. Por outro lado, os dados revelaram uma deficiência grave para alunos deste nível no que toca ao uso da grafia katakana. Também consideramos relativamente grave o fato de que dois entre três alunos que traduziram do português para o japonês não conseguiram usar a forma apropriada do verbo comprar, 買う Este é um dado que, de um lado, mostra a necessidade de outras pesquisas para avaliar o uso de verbos pelos alunos, e, de outro, desenvolver exercícios para suprir lacunas porventura existentes no ensino do uso de verbos.

Já no segundo grupo, tornou-se patente a dificuldade que os alunos têm em usar os assim chamados substantivos formais, keishikimeishi ${ }^{15}$ (Ota, 1992). No entanto, apesar da dificuldade da compreensão e do uso dos substantivos formais, a compreensão geral dos alunos não se revela por este método. $O$ primeiro aluno não deu conta de traduzir a frase com a nuança embutida na mensagem principal que é a experiência vivida no passado. Analisando a frase elaborada pelo segundo aluno, está correta a tradução que fez da frase que lhe foi passada, sem a sugestão de experiência do passado. Se o primeiro aluno tivesse sugerido em sua frase a experiência no passado, provavelmente o resultado teria sido outro. É preciso, pois, estar alerta para não generalizar a tendência dos alunos, usando apenas um método.

No entanto, também constitui erro grave da falta de atenção no uso do tempo do verbo observado no terceiro aluno. Portanto, os alunos do $8^{\circ}$ semestre, em geral, ainda se defrontam com problemas básicos em geral. É preciso ainda melhorar o teste a ser aplicado, mas bem estruturado, pode ser um instrumento útil para medir o nível de aprendizagem.

Por outro lado, no segundo semestre de 2010 , foi solicitado a alunos do $7^{\circ}$ semestre que escolhessem uma estrutura gramatical para apresentar seu sentido. Foi interessante notar que todos usaram a tradução em suas explanações, apesar de a tradução não ser tratada em sala de aula. Acreditamos que os alunos usaram a tradução para explicitar o sentido, e não a forma gramatical, da expressão escolhida, como uma forma de suprir as deficiências de conhecimento gramatical e estratégico necessário para explicar a estrutura gramatical propriamente dita.

15. Ota define keishikimeishi que "do ponto de vista da morfologia, ... substantivo formal é substantivo que perde, em determinada posição sintática ou em determinada ligação com outras palavras, o significado próprio que possui na sua independência" $(1992$, p.28) 
Por outro lado, vale registrar o recurso à interlíngua por um dos alunos. A estrutura escolhida por ele foi “〜となっている” , a mesma que apareceu em um dos textos analisados durante o semestre na frase “水は生命の源となっている” [ mizu wa seimei no minamoto to natteiru, "a água forma a fonte da vida (a água é considerada como fonte da vida)" ]. O aluno iniciou sua explanação alertando os demais colegas para não usar a primeira acepção do verbo なる, "tornar-se", encontrada em dicionários. Assim ele apresentou em slide:

$\mathrm{Em}$ 水はまさに（生命の源）となっています。

É possível ver por lógica que o conceito de tornar-se não se aplica necessariamente. Pois a água não se tornou um recurso indispensável em um determinado momento, ela sempre foi vital para a vida.

(slide do aluno)

Em seguida, criou frases japonesas interlinguais para contrastar a interpretação errônea:

$$
\begin{aligned}
& \text { 子どもが大人となっている。(errado) } \\
& \text { 今、新時代となっている。(errado) }
\end{aligned}
$$

Frisando que para tais sentenças é preciso usar uma combinação da partícula にcom o verbo なる, ou sejaになる, esclareceu que a estrutura“となっている” tem outro sentido pois não exprime o efeito ou resultado de uma transformação. $E$ a partir da observação de frases que usam a estrutura escolhida, ele identificou que ela é usada "para passar uma ideia de relação de importância", que, na maioria dos casos, serve-se da metáfora, concluindo que "a relação de importância geralmente é expressa através de metáforas"

Por fim, elaborou a seguinte frase para exemplificar sua explanação.

ブラジルの文化によってなんぱの技術は男の力となっています。[burajiru no bunka niyotte, nanpa no gijyutsu wa otokono chikara to natteimasu, (ele quer dizer que) "na cultura brasileira, a técnica de paquera é a força do homem"]

Para definir a estrutura “Aは Bの (metáfora) となっている”, ele apresentou assim em outro slide:

A "metáfora" quantifica a importância de B em relação á A, por fazer parte do mesmo. Mas nem sempre em sentido figurado, as vezes num sentido concreto

(slide do aluno) 
Independente da exatidão ou não da informação, sua descoberta não é absurdamente errada. De certa forma, devemos considerá-lo criativo.

No final, apresentou em outro slide as possíveis traduções para a forma por ele escolhida.

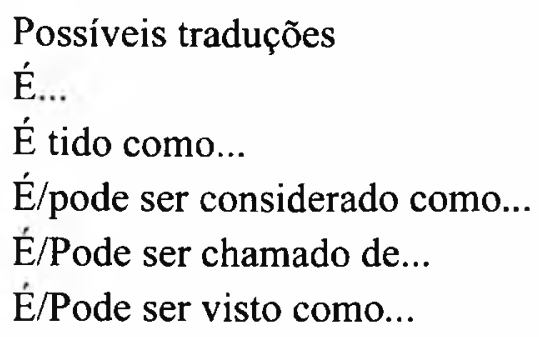

(slide do aluno)

Mesmo arriscando apresentar algumas expressões interlinguais em sua explanação, o aluno conseguiu apresentar a estrutura de forma analítica, salientando o erro a que pode induzir a tradução palavra por palavra. Decidiu, assim, apresentar uma lista de possíveis traduções da expressão para o português, embasado na explicação dada.

Destacamos esta apresentação porque conseguiu apreender o sentido, diferentemente de outros alunos que não conseguem ver o que está oculto. Por exemplo, uma aluna que tratou a expressão “AはB と比べて $[A$ wa B to kurabete (Comparando A com B]", apresentou somente um slide, começando com a tradução "em relação a ....", em que nem aparece o verbo "comparar", nem se refere à estrutura da frase. Ela se preocupa apenas com o sentido final, sem indagar quais as estruturas usadas pela língua para chegar a isso.

Ainda não tivemos a oportunidade de aplicar testes que avaliem o nível de compreensão dos alunos, por meio de explanações por eles feitas, usando a tradução. Propomo-nos, no entanto, a verificar o uso da tradução pelo aluno como uma ferramenta de análise da língua, pela meta-tradução, com vistas a conduzi-los à percepção das diferenças e semelhanças entre as duas línguas envolvidas.

\section{Considerações Finais}

Partindo da concepção da tradução como uma habilidade inata, constata-se que recorremos à tradução mental sempre que temos a necessidade de mediar línguas em contato. $O$ primeiro momento dessa mediação, no contexto escolar brasileiro, pode ocorrer na sala de aula de ensino de LE. Considerando-se que a tradução é automaticamente engajada em nossa aprendizagem mental, ela se torna uma eficaz ferramenta para entendermos melhor outra(s) língua(s). 
Cunningham (2000), citando Richards e Rodgers (1986:4) ${ }^{16}$ receia que, apesar do seu uso freqüente em qualquer lugar do mundo, não há uma discussão metodológica sobre o uso da tradução no ensino. Muito ao contrário, todos tendem a condenar este uso da tradução.

Como uma primeira tentativa nossa, apresentamos alguns casos verificados em sala de aula, envolvendo atividades de tradução dos alunos. E a tradução revelou-se uma boa ferramenta para revitalizar a habilidade analítica dos alunos, levando-os a notar diferenças e semelhanças entre a LM e a LE, garantindo a promoção da atividade cognitiva do aluno.

\section{Referências Bibliográficas}

ALEGRE, T. A Tradução Pedagógica de Actual Ensino de Línguas: Caso Do Alemão. IN: Encontro Nacional sobre o Ensino das Línguas Vivas no Ensino Superior, $5^{\circ} 2000$. Encontrado no site: http://ler.letras.up.pt/site/default.aspx?qry=id03id1246\&sum=sim

BIALYSTOK, E \& SHARWOOD SMITH, M. Interlanguage is not a State of Mind: na Evaluation of the Construct for Second-Language Acquisition. IN: Applied Linguistics 6 (2).1985. Encontrado no site: http://www.li.suu.edu/librarv/circulation/Kirk/span4512rkBialystokandSharwoodSmithSp2010.pdf

BROWN, H.D. Principles of Language Learning and Teaching. 4a.ed. Longman, New York. 2000.

CUNNINGHAM,C. Translation in the Classroom: A Useful Tool for Second language Acquisition. CELS, University of Birmingham. 2000. Encontrado no site: http://www.cels. bham.ac.uk/resources/essays/cindyc2.pdf

DARWISH, A. Is Translation Natural? Internet Electronic Publishing, 2000. Encontrado no site: http://www.translocutions.com/translation/natural.pdf

FERRER, V. Using the Mother Tongue to Promote Noticing: Translation as a Way of Scaffolding Learner Language. Internet Electronic Publishing, 2005. Encontrado no site:

http://www.teachenglishworldwide.com/Articles/Ferrer_mother\%20tongue $\% 20$ to\%20promote\%20noticing.pdf

HOUSE, J. Translation. Oxford Press, Oxford, 2009.

Kasmer, W. The role of Translation in the EFL / ESL classroom. CELS, University of Birmingham. 1999. Encontrado no site: http://www.cels.bham.ac.uk/resources/essavs/ kasmer2.pdf

LÖRSCHER, W. Process oriented Research into Translation and Implications for Translation Teaching. In: Letras, 8. Santa Maria, 1994.

16. RICHARDS, J. and RODGERS, T. Approaches and Methods in Language Teaching, Cambridge, CUP. 1986. 
MATIOLLI, G. On native language instructions and making do with words: linguistically homogenous classrooms and native language use. IN: English Teaching Forum. Outubro, 2004. Encontrado no site: http://eca.state.gov/forum/vols/vol42/no4/p20.htm

NAZARY,M. The role of L1 in L2 acquisition: Attitudes of Iranian university students. IN: Novitas-ROYAL, vol. 2(2), 138-153. 2008. Encontrado no site: http://www.novitasroyal. org/nazary.html

PAIVA, M. G. G. "Os desafios (?) do ensinar a ler e a escrever em língua estrangeira" In.: NEVES, I.B.; SOUZA, J. V. (Orgs.). Ler e escrever, compromisso de todos. Porto Alegre: Ed. da UFRGS, 1998.

SEKINO, K. Método protocol dialogado: traçando o raciocínio dos aprendizes de língua japonesa. IN: Anais do XX Encontro Nacional de Professores Universitários de Língua e Literatura e Cultura Japonesa. Universidade de São Paulo.São Paulo, 2009

SHIYAB, S \& ABDULLATEEF, M. Translation and Foreign Language Teaching. IN: Language and Translation, vol. 13. J.King Saud Univ. 2001. Encontrado no site: http://citeseerx. ist.psu.edu

USADIATI, W. Contribution of L1 in EFL teaching. IN: $\mathbf{k} @$ ta, Vol 11, No 2. 2009. Encontrado no site: http://puslit2.petra.ac.id/ejoumal/index.php/ing/article/viewArticle/17892 